\title{
openheart Research priorities in advanced heart failure: James Lind alliance priority setting partnership
}

Clare J Taylor (D) , ${ }^{1}$ Alyson L Huntley, ${ }^{2}$ John Burden, ${ }^{3}$ Amy Gadoud, ${ }^{4}$ Toto Gronlund, ${ }^{5}$ Nicholas Robert Jones (D) , ${ }^{6}$ Eleanor Wicks, ${ }^{7}$ Sara McKelvie, ${ }^{8}$ Kit Byatt, ${ }^{9}$ Richard Lehman, ${ }^{10}$ Anna King, ${ }^{11}$ Bev Mumford, ${ }^{12}$ Gene Feder, ${ }^{2}$ Jonathan Mant, ${ }^{13}$ Richard Hobbs, ${ }^{14}$ Rachel Johnson (iD) ${ }^{15}$

To cite: Taylor CJ, Huntley AL, Burden J, et al. Research priorities in advanced heart failure: James Lind alliance priority setting partnership. Open Heart 2020;7:e001258. doi:10.1136/ openhrt-2020-001258

Received 3 February 2020 Revised 3 April 2020 Accepted 21 April 2020
Check for updates

(c) Author(s) (or their employer(s)) 2020. Re-use permitted under CC BY-NC. No commercial re-use. See rights and permissions. Published by BMJ.

For numbered affiliations see end of article.

Correspondence to Dr Rachel Johnson; epraj@ bristol.ac.uk

\section{ABSTRACT}

Objective To determine research priorities in advanced heart failure (HF) for patients, carers and healthcare professionals.

Methods Priority setting partnership using the systematic James Lind Alliance method for ranking and setting research priorities. An initial open survey of patients, carers and healthcare professionals identified respondents' questions, which were categorised to produce a list of summary research questions; questions already answered in existing literature were removed. In a second survey of patients, carers and healthcare professionals, respondents ranked the summary research questions in order of priority. The top 25 unanswered research priorities were then considered at a face-to-face workshop using nominal group technique to agree on a 'top 10'.

Results 192 respondents submitted 489 responses each containing one or more research uncertainty. Outof-scope questions (35) were removed, and collating the responses produced 80 summary questions. Questions already answered in the literature (15) were removed. In the second survey, 65 questions were ranked by 128 respondents. The top 10 priorities were developed at a consensus meeting of stakeholders and included a focus on quality of life, psychological support, the impact on carers, role of the charity sector and managing prognostic uncertainty. Ranked priorities by physicians and patients were remarkably divergent.

Conclusions Engaging stakeholders in setting research priorities led to a novel set of research questions that might not have otherwise been considered. These priorities can be used by researchers and funders to direct future research towards the areas which matter most to people living with advanced HF.

\section{INTRODUCTION}

Heart failure (HF) is a common condition affecting one to two in every hundred adults in the $\mathrm{UK}^{1}$ and one in six people aged over 85 years. $^{2}$ People with HF can experience symptoms of breathlessness, tiredness and leg swelling; have a reduced quality of life; and may require hospital admission. ${ }^{3}$ Treatment

\section{Key messages}

What is already known about this subject?

- Research priorities are typically set by funders and researchers, yet it is known that involving stakeholders, including patients and clinicians, can produce research that is more credible and relevant to stakeholders.

What does this study add?

- In this study, research priorities for advanced heart failure (HF) were developed in collaboration with patients, carers and clinicians using an extensively validated method. The resultant top 10 research priorities for advanced HF can be used by researchers and funders to influence the HF research agenda.

How might this impact on clinical practice?

- Through influencing the HF research agenda, this has the potential to lead to credible, relevant research that focuses on the questions important to patients, carers and clinicians.

of HF includes medications, exercise-based rehabilitation, device therapies and, in a small number of cases, transplantation. ${ }^{45}$

There are many areas of healthcare, including the management of people with advanced $\mathrm{HF}$, where the right treatment approach is sometimes unclear. ${ }^{6}$ In advanced $\mathrm{HF}$, this may reflect the fact there is significant heterogeneity in important disease characteristics such as aetiology, treatment and disease course. Advanced HF guidelines and policy documents often focus on hospital inpatients. ${ }^{7}$ The majority of people with $\mathrm{HF}$ are community-dwelling older people with multiple comorbidities who are underrepresented in research studies. ${ }^{89}$

Traditionally, researchers formulate the research questions they feel are most important and apply to funders to undertake work which will provide an answer. In the field of advanced HF, research has focused 
on younger, often male patients. In recent years, national funding bodies have advocated for more involvement of patients in setting the research agenda, notably through National Instute for Health Research (NIHR) INVOLVE, a government-funded programme to support active public involvement in research. The James Lind Alliance (JLA), a non-profit-making initiative partly funded by the National Institute for Health Research (NIHR), is committed to ensuring those most affected by a condition are involved in prioritising research by bringing together patients with the condition, their carers and clinicians to determine the key priorities for future research. ${ }^{1011}$ The JLA's method for involving stakeholders, including patients and clinicians, in setting research priorities has been extensively tested and validated across a wide range of conditions accessible online (http://www.jla.nihr.ac. $\mathrm{uk}$ /priority-setting-partnerships) and is recognised as the best currently available method for undertaking this.

The perceived research priorities for people living with advanced HF in a community setting are unknown. Our objective, therefore, was to work with patients, carers and clinicians to establish, for the first time, the research priorities for people with advanced HF using the systematic JLA priority setting method.

\section{METHODS}

Priority setting involves gathering data from key stakeholders to arrive at a prioritised set of questions which can be answered through future research projects. This differs from standard research studies as the aim was to find research questions rather than answers. The most robust and well-tested method for priority setting with healthcare stakeholders has been developed by the JLA, and the full methodology is described in their published guidance. ${ }^{11}$ The process for the advanced HF priority setting partnership (PSP) is summarised in figure 1.

\section{Setting up the PSP}

The PSP was established in April 2017 as a collaboration between clinicians involved in managing people with advanced HF, led by two general practitioners (GPs) with expertise in HF management and research (CJT and RJ). Data analysis was carried out by an experienced information specialist (ALH), a senior evidence synthesis scientist with significant experience of working on applied health research studies including those focused on HF. The NIHR Evaluation, Trials and Studies Coordinating Centre allocated a JLA adviser to help set up the PSP and provide support throughout the process (TG).

A steering group oversaw the PSP, meeting eight times during the process. The steering group comprised 18 members (6 men and 12 women), including 4 patients, 2 carers, 6 healthcare professionals (HF nurse specialist, palliative care nurse, cardiologist, geriatrician, palliative medicine consultant and GP), the core PSP team (CJT, RJ, ALH and TG) and one observer. Members had links to wider partner networks, including charities, patient groups and professional organisations.

\section{Scope}

The scope of this PSP was the management of adults (age 18 years and over) with advanced HF in the community, including physical health (symptoms and treatments), emotional well-being and support services, but excluding HF diagnosis. The steering group highlighted the challenge of identifying people with advanced HF in this context: for stakeholders to identify the PSP as relevant to them, a definition of advanced HF that would be meaningful to patients and carers was required. There is no universally agreed definition for advanced HF either within the clinical community or among patient and carer groups. The European Society for Cardiology definition includes investigation findings, but patients themselves are unlikely to know detailed echocardiogram results. ${ }^{12}$ For this PSP, we defined a patient with advanced $\mathrm{HF}$ in the community as 'a person with a known diagnosis of HF who has symptoms, such as breathlessness, which impact on their quality of life, and may require them to take multiple medications and be admitted to hospital but who are not currently an inpatient.'

\section{Patient and public involvement and engagement (PPIE)}

The JLA process aims to equally involve people with lived experience of $\mathrm{HF}$ and their healthcare professionals in setting priorities for research. However, the steering group recognised that people with advanced HF in the community may be a particularly hard-to-reach group, so a separate PPIE group (seven members) was established to work alongside the steering group and provide additional advice from the perspective of patients with advanced HF. The PPIE group provided input into the development of both the initial and interim prioritisation surveys. Specifically, the group provided feedback on the wording of the survey (readability and ease of understanding), and the usability of the online and paper versions.

\section{Identifying unanswered questions}

The aim of the initial survey was to collect raw, unanswered questions from patients, clinicians and carers with experience of advanced HF. The survey was designed and piloted by the steering group, together with the PPIE group. In designing the survey questions, the steering group considered question formats used in previous PSPs. Prompts, including example answers, were included at the recommendation of patients and carers in the PPIE group/steering group to help respondents understand how to answer the questions. The survey was open from June to September 2018 and was available in online, paper and easy-read versions. Respondents were asked three open questions about the physical and emotional impacts of advanced HF, and the treatment, support or help provided for people with the condition (figure 2).

To encourage survey completion, data collection was kept to a minimum and was limited to factors that were 


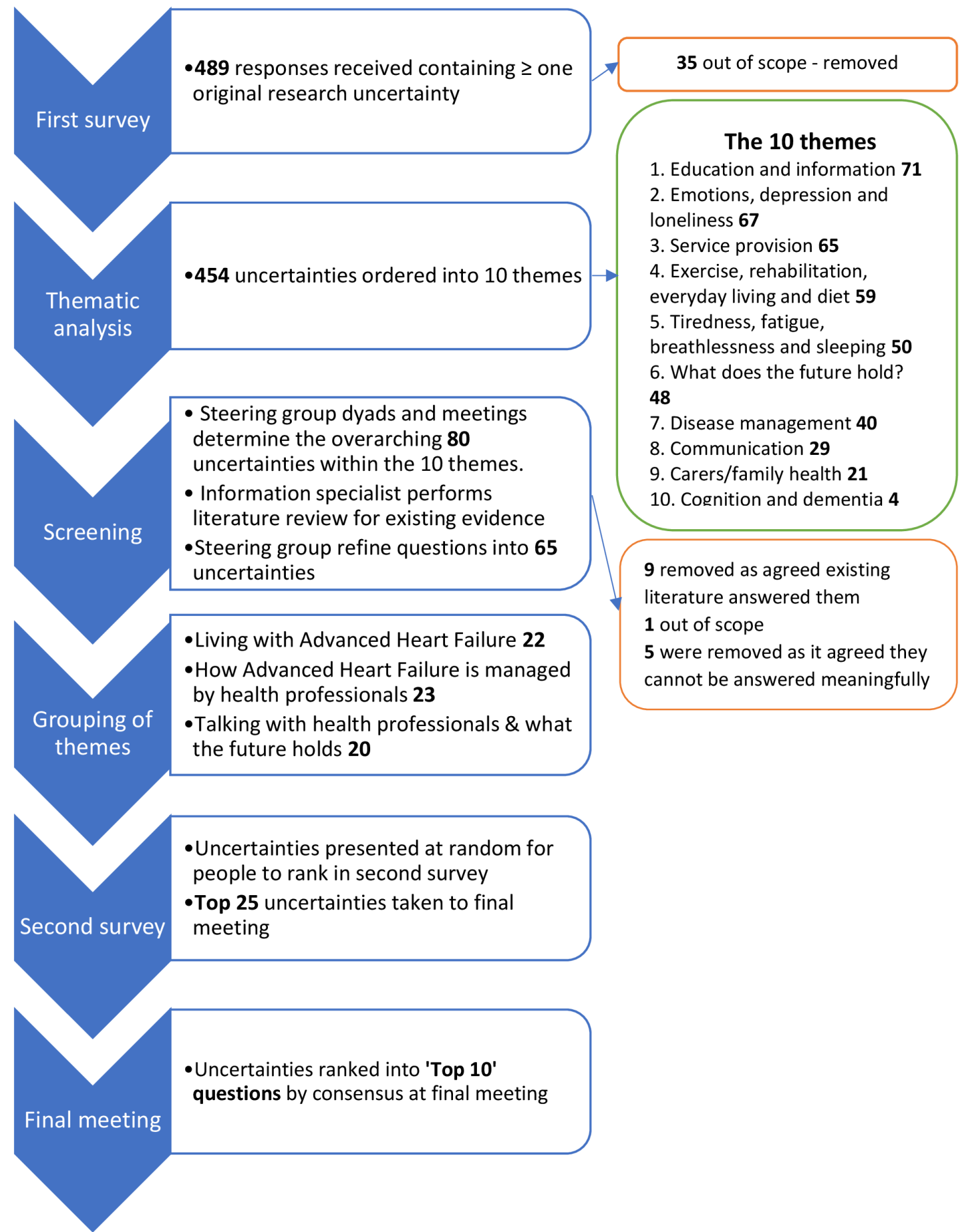

Figure 1 James Lind Alliance process overview.

likely to influence respondents' suggested questions. Patients were asked basic demographic details (age, sex and ethnicity), and healthcare professionals were asked to define their professional group in order to check whether we were successful in sampling across these groups.

The JLA process requires surveys to be widely distributed through multiple channels and open access to patients and the public. The overall sample size or 'denominator' for the survey is therefore not known. Steering group members raised awareness of the survey through their respective networks, for example, charities, including Pumping Marvellous, linked to the survey through their social media, and clinicians handed out surveys in practices and outpatient cardiology clinics. Social media was used to promote the survey widely, and relevant charities, including Carers UK and the British Heart Foundation, were contacted.

\section{Refining questions}

Survey responses ( 489 responses to individual survey questions from 192 respondents) were assembled, categorised 
1. What questions do you have about the physical impact of advanced heart failure?

\section{For example: \\ What can help me with my tiredness? \\ What can help me sleep better? \\ Will exercise help my heart failure?}

2. What questions do you have about the emotional impact of advanced heart failure?

\section{For example:}

Who is it best to see if I am feeling low?

Will yoga help me with my anxiety about heart failure?

Is it safe for me to take antidepressants?

3. What questions do you have about the treatment, support or help provided for people with advanced heart failure?

\section{For example:}

Who should I talk to about my medication- nurse or doctor?

How can I get a GP appointment if I start to feel worse?

Figure 2 Initial survey questions: Main question, Prompts.

and refined by the steering group to form summary questions. This was a collaborative process: all submitted questions were considered, and questions with a similar theme (eg, questions about how to use diuretics) were iteratively grouped into categories (figure 1). Working in groups that included a mix of healthcare professional and patient or carer, questions within categories were discussed, and similar or duplicate questions were combined where appropriate, and questions deemed out of scope were referred back to the wider steering group to consider whether they should be removed. This process resulted in the list of summary questions for the second (prioritisation) survey. The JLA adviser ensured contribution of all steering group members to this process. Systematic reviews and guidelines were identified and checked by the information specialist and PPIE lead, referring to clinical members of the steering group when needed, to see to what extent these refined questions had, or had not, been answered by previous research. Some questions could be answered with existing information and were removed from the prioritisation process at this stage.

\section{Interim prioritisation}

A second 'prioritisation' survey was distributed via the same multiple channels as the first survey and was intended to reach an equally wide audience. A link to the second survey was posted on the PSP website. Respondents to the first survey who had provided contact details were invited to complete this second survey. Steering group members also distributed the survey through their stakeholder networks.

The aim of the interim prioritisation stage was to proceed from the longer list of questions generated from the initial survey to a shorter list, which could be taken to the final workshop. Respondents were asked to choose their 'top 10' from a shortlist of summary questions and provide basic demographic details. We used the online platform Optimal Workshop Card Sort for the survey. Using this platform, we presented questions in a randomly generated order to avoid respondents preferencing questions at the top of the list; respondents were asked to choose their top 10 questions. Paper copies of the survey were also available. The second survey was open from January 2019 to February 2019. Responses to the second survey were organised by the number of respondents choosing each question and by professional group. In accordance with the PSP process, the highestranking questions were included in a shortlist of 25 questions to be discussed at the final workshop.

\section{Final workshop}

The final prioritisation stage was conducted in a faceto-face meeting attended by a total of 30 participants, including patients, carers and healthcare professionals, most of whom had not been involved in the PSP process. The workshop was observed by members of the steering group, researchers and the British Heart Foundation, which funds cardiovascular research. Three experienced JLA advisers facilitated group discussions to build consensus towards the final top 10 research priorities using the nominal group technique. ${ }^{13}$ Workshop attendees worked in three groups, including a mix of patients, carers and healthcare professionals. Facilitated by the JLA advisers, the groups discussed the shortlist of questions and proposed a priority order, before groups were alternated and the process repeated. The proposed ordering of the three groups was collated and presented to the whole group, and in a final facilitated discussion, the top 10 priorities were agreed.

\section{RESULTS \\ Initial survey}

A total of 192 respondents completed the initial survey. These included 74 patients, 17 carers, 92 health professionals and 9 others. Only patients were asked for demographic details (table 1 ).

\section{Data analysis}

A total of 489 responses which contained one or more research questions were submitted in response to the survey questions on physical health, emotional well-being and treatment. Thirty-five questions were removed as they were out of scope (eg, questions related to diagnosis), and the remaining 454 were ordered into 10 categories (figure 1).

The research questions were combined, with duplicates removed, to form 80 summary questions. These were checked against existing literature and 15 answered questions were removed. The remaining 65 summary questions were grouped into three key themes: living with advanced HF (22), how advanced HF is managed by the health service (23) and talking with health professionals about what the future holds (20). These were included in the second survey with the questions presented in a random order (appendix 1). 
Table 1 Role of participants and demographic details for patients with heart failure in the initial and interim surveys

\begin{tabular}{|c|c|c|}
\hline & $\begin{array}{l}\text { Initial survey } \\
\text { (n) }\end{array}$ & $\begin{array}{l}\text { Interim } \\
\text { survey (n) }\end{array}$ \\
\hline \multicolumn{3}{|l|}{ Role } \\
\hline Patient & 74 & 17 \\
\hline Carer & 17 & 15 \\
\hline Healthcare professional & 92 & 96 \\
\hline Other & 9 & 0 \\
\hline \multicolumn{3}{|l|}{ Age (years) (patients only) } \\
\hline$<40$ & 6 & 2 \\
\hline $41-50$ & 14 & 2 \\
\hline $51-60$ & 18 & 4 \\
\hline $61-70$ & 19 & 3 \\
\hline $71-80$ & 12 & 2 \\
\hline$>80$ & 5 & 0 \\
\hline \multicolumn{3}{|l|}{ Sex (patients only) } \\
\hline Male & 34 & 4 \\
\hline Female & 39 & 10 \\
\hline Not stated & 1 & 3 \\
\hline \multicolumn{3}{|l|}{ Ethnicity (patients only) } \\
\hline White British & 69 & 16 \\
\hline Black African & 1 & 0 \\
\hline Mixed & 2 & 0 \\
\hline Not stated & 2 & 1 \\
\hline
\end{tabular}

\section{Interim prioritisation}

Respondents were asked to pick their top 10 questions from a list of 65 summary questions. A total of 128 respondents completed the survey online using Card Sort, with no paper surveys being returned: 17 patients, 15 carers and 96 healthcare professionals. The top ranked priorities in the interim survey were different between patients/carers and healthcare professionals: of the top 13 priorities chosen by each group (patients/carers and healthcare professionals), only one question was chosen by both groups (figure 3). To ensure a balance in the shortlist for the final workshop, the top 13 priorities for the patient/carers and the top 13 for the healthcare professional groups (ie, including one priority which both groups ranked highly) were included on the shortlist.

\section{Final workshop}

The final workshop included 26 participants: 5 patients, 3 carers, 6 GPs, 2 HF nurse specialists, a cardiologist, a geriatrician, 3 GP cardiologists, a physiotherapist, a cardiology research nurse, 2 charity representatives and a patient and public involvement facilitator. The top 10 research priorities determined at the final workshop are shown in table 2 . The top 10 priorities included questions that had been shortlisted because they were in the top 13 for patients (5), healthcare professionals (4) or both (1).

\section{DISCUSSION \\ Summary}

This is the first attempt to formally identify future research priorities in advanced HF. We used the JLA method to engage patients, carers and healthcare professionals. The initial survey yielded 489 research questions which were sorted, categorised and checked against existing literature to generate a final list of 65 summary questions. These were considered in a second prioritisation survey to generate a list of 25 questions, which were taken to a final workshop where the top 10 list of research priorities was generated through consensus. Interestingly, the priorities for patients and carers differed completely from healthcare professionals in the interim survey. For patients and carers, quality of life and managing uncertainty were most important, whereas healthcare professionals' priorities comprised 'difficult conversations' and drug treatment. However, at the final prioritisation stage, patients, carers and healthcare professionals aligned in the importance of patient empowerment, end-of-life care, psychological support and the vital role of carers.

\section{Strengths and limitations}

This study has several strengths. We used an established method, one which has been used by government and charities to prioritise future funding in health services research, ${ }^{7}$ to determine research priorities of patients, carers and healthcare professionals affected by advanced HF. Our committed steering group was involved throughout, including in survey design, review and analysis of the data, and survey dissemination. Surveys were developed with patient and carer input (including those over 80 years old) and were designed to make data collection straightforward; an easy-read version of the survey was developed and made available. We attempted to access black and minority ethnic groups through our stakeholder group contacts. The initial survey was disseminated widely in a range of settings and had a good response across a range of patient age groups. The meaning of advanced HF is different between patients, carers and professional groups; our definition was designed to allow a prioritisation exercise to take place in which patients and carers could participate. The priorities for patients and carers were different from those of healthcare practitioners, which highlight the importance of conducting this type of priority setting exercise.

We acknowledge several limitations. We did not collect patient-identifying information; therefore, we are able to describe the survey respondents only in limited terms, and are unable to draw comparisons between the first and second survey respondents. We did not collect data on deprivation or educational level, but more articulate and engaged people are more likely to complete surveys, which may have introduced a bias in terms of 


\begin{tabular}{|c|c|c|}
\hline \multirow{2}{*}{ 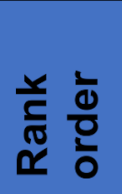 } & \multicolumn{2}{|c|}{ Top 13 ranked priorities, by respondent group } \\
\hline & Health professionals & Patients/Carers \\
\hline 1 & $\begin{array}{l}\text { How do health professional's best manage } \\
\text { chronic kidney disease and advanced heart } \\
\text { failure? a. What medication is best to use? b. } \\
\text { How to manage diuretics c. Is metolazone or iv } \\
\text { furosemide better? }\end{array}$ & $\begin{array}{l}\text { What amount and type of exercise is safe and } \\
\text { effective for people with advanced heart failure? }\end{array}$ \\
\hline 2 & $\begin{array}{l}\text { How do we break down barriers for patients } \\
\text { with advanced heart failure, carers and health } \\
\text { professionals to enable talking about end of life } \\
\text { care? }\end{array}$ & $\begin{array}{l}\text { Which treatments have the biggest impact on the quality } \\
\text { of life of people with advanced heart failure?** }\end{array}$ \\
\hline 3 & $\begin{array}{l}\text { What is the most effective way to use diuretics } \\
\text { in advanced heart failure, with respect to, fluid } \\
\text { overload, kidney function, survival \& quality of } \\
\text { life? }\end{array}$ & $\begin{array}{l}\text { Do health professionals understand the life / activity / } \\
\text { functional consequences of each medicine? }\end{array}$ \\
\hline 4 & $\begin{array}{l}\text { Which treatments have the biggest impact on } \\
\text { the quality of life of people with advanced heart } \\
\text { failure?** }\end{array}$ & $\begin{array}{l}\text { What helps with symptoms from peripheral oedema } \\
\text { experienced by people with advanced heart failure? For } \\
\text { example, massage, exercise }\end{array}$ \\
\hline 5 & $\begin{array}{l}\text { How do health professionals respond when } \\
\text { people with advanced heart failure ask 'When } \\
\text { am I going to die? Are we talking days, months, } \\
\text { years? What about sudden death?' }\end{array}$ & $\begin{array}{l}\text { How do health professionals explain how advanced heart } \\
\text { failure progresses and what that means for patients' } \\
\text { symptoms? }\end{array}$ \\
\hline 6 & $\begin{array}{l}\text { Can the long-term care needs of people with } \\
\text { advanced heart failure be better met by closer } \\
\text { cooperation between heart failure and palliative } \\
\text { care teams? }\end{array}$ & $\begin{array}{l}\text { How can the work of heart failure charities be better } \\
\text { integrated with NHS services to optimise the care of } \\
\text { people with advanced heart failure? }\end{array}$ \\
\hline 7 & $\begin{array}{l}\text { How can we distinguish between co-morbidities } \\
\text { (other chronic conditions) for example: } \\
\text { COPD/chest infection \& advanced heart failure? }\end{array}$ & $\begin{array}{l}\text { How do people get support to continue as their heart } \\
\text { failure becomes more advanced? }\end{array}$ \\
\hline 8 & $\begin{array}{l}\text { What percentage of people with advanced heart } \\
\text { failure have advanced care plan (ACP) } \\
\text { discussions? }\end{array}$ & $\begin{array}{l}\text { Which approaches are effective in reducing fatigue in } \\
\text { people with advanced heart failure? }\end{array}$ \\
\hline 9 & $\begin{array}{l}\text { What is the most empowering and effective } \\
\text { education and self-management advice for } \\
\text { people with advanced heart failure and carer? } \\
\text { For example, dealing with fatigue. }\end{array}$ & $\begin{array}{l}\text { Is there an 'App' to help people manage advanced heart } \\
\text { failure? }\end{array}$ \\
\hline 10 & $\begin{array}{l}\text { What is the optimum time to discuss } \\
\text { deactivation of ICDs (implants) and discuss } \\
\text { palliative care with people with advanced heart } \\
\text { failure? }\end{array}$ & $\begin{array}{l}\text { What are the benefits of asking a person with advanced } \\
\text { heart failure 'what is important to them'? }\end{array}$ \\
\hline 11 & $\begin{array}{l}\text { How can healthcare professionals manage the } \\
\text { expectations of people with advanced heart } \\
\text { failure? For example, uncertainty }\end{array}$ & $\begin{array}{l}\text { What support would be most effective for carers of } \\
\text { people with advanced heart failure for example support } \\
\text { groups }\end{array}$ \\
\hline 12 & $\begin{array}{l}\text { Which approaches, in additional to standard } \\
\text { therapies, are effective in supporting breathless } \\
\text { people with advanced heart failure? }\end{array}$ & $\begin{array}{l}\text { How can advanced heart failure patients and } \\
\text { professionals be helped to communicate about } \\
\text { symptoms that are difficult to express such as anxiety } \\
\text { and low mood? }\end{array}$ \\
\hline 13 & $\begin{array}{l}\text { Which approaches are effective in helping } \\
\text { people with advanced heart failure to have a } \\
\text { good night's sleep? }\end{array}$ & $\begin{array}{l}\text { Can the long-term care needs of people with advanced } \\
\text { heart failure be better met by closer cooperation } \\
\text { between heart failure and palliative care teams? }\end{array}$ \\
\hline
\end{tabular}

${ }^{* *}$ question ranked in top 13 by both respondent groups

Figure 3 Twenty-five shortlisted questions discussed at the final workshop. COPD, chronic obstructive pulmonary disease; ICD, implantable cardioverter-defibrillator. 


\begin{tabular}{|c|c|c|}
\hline & Research priority & $\begin{array}{l}\text { Group (patients, carers or healthcare } \\
\text { professionals) whose survey responses were } \\
\text { incorporated into this research question }\end{array}$ \\
\hline 1. & $\begin{array}{l}\text { Which treatments have the biggest impact on the quality of life of people with } \\
\text { advanced HF? }\end{array}$ & Patients \\
\hline 2. & $\begin{array}{l}\text { What amount and type of exercise is safe and effective for people with advanced } \\
\text { HF? }\end{array}$ & Patients and healthcare professionals \\
\hline 3. & $\begin{array}{l}\text { What is the most empowering and effective education and self-management } \\
\text { advice for people with advanced HF and their carers? (eg, dealing with fatigue) }\end{array}$ & Patients, carers and healthcare professionals \\
\hline 4. & $\begin{array}{l}\text { How can the work of HF charities be better integrated with NHS services to } \\
\text { optimise the care of people with advanced HF? }\end{array}$ & Patients \\
\hline 5. & $\begin{array}{l}\text { Which approaches, in addition to standard therapies, are effective in supporting } \\
\text { breathlessness in people with advanced HF? }\end{array}$ & Healthcare professionals \\
\hline 6. & $\begin{array}{l}\text { How do we break down barriers for patients with advanced HF, carers and health } \\
\text { professionals to enable talking about end of life care? }\end{array}$ & Patients, carers and healthcare professionals \\
\hline 7. & $\begin{array}{l}\text { What are the benefits of asking a person with advanced HF 'what is important to } \\
\text { you'? }\end{array}$ & Healthcare professionals \\
\hline 8. & $\begin{array}{l}\text { What is the most effective way to use diuretics in advanced HF, with respect to } \\
\text { fluid overload, kidney function, survival and quality of life? }\end{array}$ & Healthcare professionals \\
\hline 9. & $\begin{array}{l}\text { How can patients with advanced HF and professionals be helped to } \\
\text { communicate about symptoms that are difficult to express such as anxiety and } \\
\text { low mood? }\end{array}$ & Patients and healthcare professionals \\
\hline 10. & $\begin{array}{l}\text { What support would be most effective for carers of people with advanced HF? } \\
\text { (eg, support groups) }\end{array}$ & Patients and healthcare professionals \\
\hline
\end{tabular}

HF, heart failure.

socioeconomic gradient. ${ }^{14}$ The second survey had a lower response rate.

We found it challenging to engage with the over 80-year age group despite efforts to access older adults through steering group member networks, and our success at reaching black and minority ethnic groups was limited.

\section{Comparison with existing literature}

Previous PSPs have covered a variety of healthcare topics, including diabetes mellitus, inflammatory bowel disease, renal transplantation, fragility fractures and congenital heart disease. ${ }^{15-19}$ Each PSP has used existing networks to engage relevant groups of patients, carers and healthcare professionals. Some diseases, such as diabetes mellitus, have large, often well-engaged patient groups, so the number of respondents was higher. ${ }^{15} \mathrm{HF}$ is a difficult, often frightening, term which is not well recognised by the general public. ${ }^{20}$ Even people with a diagnosis of $\mathrm{HF}$ may not always know they have the condition. HF also rarely occurs in isolation, with over two-thirds of people with HF living with three or more comorbidities. ${ }^{1}$ This may mean HF is not their main source of concern or focus of healthcare and that people may be uncertain which of their symptoms are attributable to HF and therefore a research uncertainty in this area.

The JLA process yielded a different set of priorities for patients/carers and healthcare professionals at the interim survey stage. Other PSPs, such as the head and neck cancer PSP, had similar results. ${ }^{21}$ Patients and carers wanted to understand more about their condition in the advanced stages of disease, feel empowered to safely self-manage and be able to have conversations with healthcare professionals about their future. Healthcare professionals prioritised a more medical model, with questions around drug management and the provision of advanced care planning documentation. They also felt research around end-of-life conversations was needed. This supports previous qualitative research which found patients did want to have conversations about prognosis and end-of-life care, but clinicians often feared causing premature alarm and destroying hope and so waited for patients to give cues about wanting these discussions. ${ }^{22} 23$

\section{Policy and future research}

In this study, we have identified research areas most important to patients and those supporting their care. The priorities identified reflect a change in focus to that of major HF research funders, whose research often focuses on understanding biological mechanisms and treatments to address these and on outcomes including disease measures and health service use. ${ }^{24}{ }^{25}$ Guidelines for chronic HF management reflect the available evidence described previously and do not directly address many of the priorities identified in this JLA process. ${ }^{4}$ Addressing the questions identified within this top 10 requires the use of multiple research methods, including qualitative approaches in contrast to the traditional randomised clinical trial approach. This highlights the value of asking 
patients, carers and frontline healthcare professionals for their ideas on research and what they feel is most important for people living with the condition. Research prioritisation in the UK and globally relies on governments and research funders to set the agenda. This can be influenced by charities and lobby groups, and incorporated in guideline and policy documents. ${ }^{45223}$ Governments and funders should recognise the role of a formal prioritisation processes, such as the JLA method, in determining funding priorities. As recently encouraged by NIHR leadership, this report should be used to inform researchers applying for funding to take forward these research priorities. For advanced HF, a focus on quality of life, managing uncertainty and the role of carers and charities should be included in the future research agenda.

\section{Author affiliations}

${ }^{1}$ Nuffield Department of Primary Care Health Sciences, University of Oxford, Oxford, UK

${ }^{2}$ Bristol Medical School, University of Bristol Faculty of Health Sciences, Bristol, UK ${ }^{3}$ Patient Collaborator, Hertfordshire, UK

${ }^{4}$ Lancaster Medical School, Lancaster University, Lancaster, UK

${ }^{5}$ James Lind Alliance, University of Southampton, Southampton, UK

${ }^{6}$ Primary Care Health Sciences, University of Oxford Department of Primary Care Health Sciences, Oxford, UK

${ }^{7}$ Radcliffe Department of Medicine, University of Oxford, Oxford, UK

${ }^{8}$ Emergency Multidisciplinary Unit, Oxford Health NHS Foundation Trust, Oxford, UK ${ }^{9}$ Retired, Hereford, UK

${ }^{10}$ Institute of Applied Health Research, University of Birmingham, Birmingham, UK

${ }^{11}$ Faculty of Medicine and Dentistry, University of Bristol, Bristol, UK

${ }^{12}$ Community Heart Failure Service, Bristol Community Health CIC, Bristol, UK

${ }^{13}$ Department of Public Health and Primary Care, University of Cambridge School of Clinical Medicine, Cambridge, UK

${ }^{14}$ Division of Public Health and Primary Health Care, University of Oxford, Oxford, UK ${ }^{15}$ Population Health Sciences, Bristol Medical School, University of Bristol, Bristol, UK

\section{Twitter Rachel Johnson @?rjohnsonridd}

Acknowledgements We acknowledge the patients, carers and healthcare professionals who formed the steering group, responded to the surveys and/or attended the final workshop. Thank you to Ms Sarah Morrish, our priority setting partnership coordinator, for her hard work.

Contributors CJT, RJ, ALH, AG, RL, GF, JM and RH contributed to the planning of the work. CJT and RJ co-led; AH managed study data and evidence reviews; ALH, JB, AG, TG, NRJ, EW, SMcK, RL, BM and KB were closely involved in the study conduct; AK led the patient and public involvement. CJT, RJ and ALH led the reporting of the work. RJ and CJT are guarantors for the overall content. All authors contributed to the conduct of the work and the preparation of this paper.

Funding This work was supported by the National Institute for Health Research (NIHR) School for Primary Care Research (grant numbers 368 and 382), with additional administrative support from the Oxford NIHR Biomedical Research Centre. CT and RJ are NIHR Academic Clinical Lecturers. FDRH acknowledges support from the NIHR School for Primary Care Research, NIHR CLAHRC Oxford and the NIHR Oxford BRC. JM is an NIHR Senior Investigator. The views expressed are those of the authors and not necessarily those of the NHS, the NIHR or the Department of Health and Social Care.

Competing interests CT reports personal fees from Novartis and Vifor and nonfinancial support from Roche outside the submitted work. RL reports personal fees from Yale University Open Data Access Project, outside the submitted work. KB reports other from Animal Free Research UK, and other funding from Wye Valley NHS Trust, outside the submitted work. JM reports personal fees from Bristol Myers Squibb, outside the submitted work. RH reports personal fees from Novartis, outside the submitted work.

Patient consent for publication Not required.
Ethics approval Ethical approval was not required for this study as it was a survey collecting information from patients, carers and clinicians; no identifiable information was collected from survey respondents.

Provenance and peer review Not commissioned; externally peer reviewed.

Data availability statement Data are available in a public, open access repository. The results of the priority setting partnership will be available on the James Lind Alliance website in due course.

Open access This is an open access article distributed in accordance with the Creative Commons Attribution Non Commercial (CC BY-NC 4.0) license, which permits others to distribute, remix, adapt, build upon this work non-commercially, and license their derivative works on different terms, provided the original work is properly cited, appropriate credit is given, any changes made indicated, and the use is non-commercial. See: http://creativecommons.org/licenses/by-nc/4.0/.

\section{ORCID iDs}

Clare J Taylor http://orcid.org/0000-0001-8926-2581

Nicholas Robert Jones http://orcid.org/0000-0002-0352-3785

Rachel Johnson http://orcid.org/0000-0003-0266-3433

\section{REFERENCES}

1 Conrad N, Judge A, Tran J, et al. Temporal trends and patterns in heart failure incidence: a population-based study of 4 million individuals. Lancet 2018;391:572-80.

2 Roger VL. Epidemiology of heart failure. Circ Res 2013;113:646-59.

3 Braunwald $\mathrm{E}$. The war against heart failure: the Lancet lecture. Lancet 2015;385:812-24.

4 National Institute for Health and Care Excellence. Chronic heart failure - Management of chronic heart failure in adults in primary and secondary care. NICE 2018.

5 Ponikowski P, Voors AA, Anker SD, et al. 2016 ESC Guidelines for the diagnosis and treatment of acute and chronic heart failure: The Task Force for the diagnosis and treatment of acute and chronic heart failure of the European Society of Cardiology (ESC)Developed with the special contribution of the Heart Failure Association (HFA) of the ESC. Eur Heart J 2016;37:2129-200.

6 Chalmers I. Well informed uncertainties about the effects of treatments: how should clinicians and patients respond? BMJ 2004;328:475-6.

7 Crespo-Leiro MG, Metra M, Lund LH, et al. Advanced heart failure: a position statement of the heart failure association of the European Society of cardiology. Eur J Heart Fail 2018;20:1505-35.

8 Bottle A, Goudie R, Bell D, et al. Use of hospital services by age and comorbidity after an index heart failure admission in England: an observational study. BMJ Open 2016;6:e010669.

9 Taylor CJ, Harrison C, Britt $\mathrm{H}$, et al. Heart failure and multimorbidity in Australian general practice. J Comorb 2017;7:44-9.

10 Partridge N, Scadding J. The James Lind alliance: patients and clinicians should jointly identify their priorities for clinical trials. Lancet 2004;364:1923-4.

11 James Lind Alliance. JLA Guidebook. Available: http://www.jla.nihr. ac.uk/jla-guidebook/

12 Banerjee P, Gill L, Muir V, et al. Do heart failure patients understand their diagnosis or want to know their prognosis? heart failure from a patient's perspective. Clin Med 2010;10:339-43.

13 James Lind Alliance. Coeliac UK and Innovate UK announce $£ 750 \mathrm{k}$ boost to research. Available: http://www.jla.nihr.ac.uk/news/ coeliac-uk-and-innovate-uk-announce-750k-boost-to-research-thatunlocks-important-gluten-free-challenges-highlighted-by-the-psp/ 10361

14 Strandhagen E, Berg C, Lissner L, et al. Selection bias in a population survey with registry linkage: potential effect on socioeconomic gradient in cardiovascular risk. Eur J Epidemiol 2010;25:163-72.

15 Finer S, Robb P, Cowan K, et al. Setting the top 10 research priorities to improve the health of people with type 2 diabetes: a diabetes UK-James Lind alliance priority setting partnership. Diabet Med 2018;35:862-70.

16 Hart AL, Lomer M, Verjee A, et al. What are the top 10 research questions in the treatment of inflammatory bowel disease? A priority setting partnership with the James Lind alliance. J Crohns Colitis 2017;11:204-11.

17 Knight SR, Metcalfe L, O'Donoghue K, et al. Defining priorities for future research: results of the UK kidney transplant priority setting partnership. PLoS One 2016;11:e0162136. 
18 Fernandez MA, Arnel L, Gould J, et al. Research priorities in fragility fractures of the lower limb and pelvis: a UK priority setting partnership with the James Lind alliance. BMJ Open 2018;8:e023301.

19 Drury NE, Stoll VM, Bond CJ, et al. Research priorities in singleventricle heart conditions: a United Kingdom national study. Cardiol Young 2019;29:303-9.

20 Störk S, Kavoliuniene A, Vinereanu D, et al. What does the lay public know about heart failure? findings from the heart failure awareness day initiative. Eur J Heart Fail 2016;18:66-70.

21 Lechelt LA, Rieger JM, Cowan K, et al. Top 10 research priorities in head and neck cancer: results of an Alberta priority setting partnership of patients, caregivers, family members, and clinicians. Head Neck 2018;40:544-54.

22 Nhs long term plan. Available: www.longtermplan.nhs.uk

23 All-Party Parliamentary Group on Heart Disease. . focus on heart failure: 10 recommendations to improve care and transform lives. British Heart Foundation 2016.

24 NIHR be part of research. Available: https://bepartofresearch.nihr.ac. uk/ [Accessed 31 Mar 2020].

25 Heart Failure Research, 2020. Available: https://www.bhf.org.uk/ what-we-do/our-research/heart-conditions-research/heart-failureresearch [Accessed 31 Mar 2020]. 